\title{
A CORRUPÇÃO E A VIOLAÇÃO DO DIREITO HUMANO À SAÚDE
}

\author{
Márcio Bonini Notari ${ }^{1}$ \\ Alessandra Celestino de Oliveira ${ }^{2}$
}

Recebido em: 26/06/2018

Aprovado em: 01/10/2018

\begin{abstract}
RESUMO
O presente artigo tem como objeto de estudo analisar a corrupção frente a violação do Direito Humano e Fundamental a Saúde. Será abordada, a teoria da função promocional do direito, buscando demarcar o referencial teórico de Norberto Bobbio. No segundo ponto, será feita uma abordagem acerca da literatura jurídica, notadamente, em relação aos Tratados e Convenções Internacionais de Direitos Humanos relativo ao Direito a Saúde. Por fim, a maneira pela qual os atos de corrupção cometidos por agentes públicos e privados, atingem de forma direta e indireta, esse direito fundamental de segunda dimensão, levando em conta os parâmetros e estudos realizados pelo Relatório do Instituto de Direitos Humanos de Monterrey no México (2009), buscando estabelecer formas de enfrentamento preventivas e coibitivas aos efeitos nocivos do fenômeno corruptivo, não apenas a saúde, mas ao direito a vida, a dignidade da pessoa humana, a igualdade e a discriminação.
\end{abstract}

Palavras-chave: Saúde. Direitos Humanos. Corrupção. Direitos Fundamentais.

\section{INTRODUÇÃO}

A corrupção vem se apresentando no âmbito das instituições públicas, privadas e democráticas, assim como, na sociedade civil, a partir de múltiplas faces e interfaces de condutas humanas, as quais, regra geral, está conexa ao abuso de alguma função pública, como por exemplo, um servidor estatutário de carreira (um agente fiscal), no âmbito político (deputado, senador, vereador, prefeito, governador), para atender a interesses corporativos e particulares (seja de um empresário, político ou conglomerado econômico), causando impacto

\footnotetext{
${ }^{1}$ Mestre em Direitos Sociais e Políticas Públicas pela Universidade de Santa Cruz do Sul. Especialista em Direito e Processo do Trabalho pela Anhanguera/RS.

${ }^{2}$ Doutoranda em Direito e Constitucionalização dos Institutos de Direito Privado pela Faculdade Autônoma de Direito/ FADISP. Mestre em Empreendimentos Econômicos, Desenvolvimento e Mudança Social pela UnimarSP. Especialista em Direito e Processo do Trabalho pelo Centro Universitário Filadélfia-PR.
} 
significativo nos direitos individuais de primeira dimensão, nos direitos sociais de segunda dimensão e, ainda nos direitos de terceira dimensão (meio ambiente) e nas políticas públicas, atingindo os setores mais vulneráveis e marginalizados (pobres).

$\mathrm{O}$ direito tem como função elementar enquanto ordenamento normativo, abranger o conjunto de normas de conduta e de organização, estabelecendo um todo unitário, em que a regulamentação das relações fundamentais para a convivência do grupo social, tais como, as relações de família, as relações econômicas, as relações políticas as formas através das quais o grupo social irá reagir à violação da institucionalização das sanções. Todavia, em alguns casos, poderá ser ineficiente como regulador de condutas, ainda que sejam estabelecidas regras jurídicas que tenham a missão de tutelar determinados direitos individuais e coletivos, criando deveres para o poder de Estado.

Um dos problemas a serem enfrentados no presente trabalho, diz respeito à violação do direito humano e fundamental a saúde, em razão dos atos de corrupção. Há, em tese, uma rede de relações contaminadoras nessa área, em razão de emendas orçamentárias supressivas, aditivas/realocativas, em tese, lícitas, as quais afetam intensamente todos os bens e interesses públicos que sofreram restrição. Os recursos perdidos poderiam ser utilizados na compra de medicamentos, equipamentos hospitalares, na ampliação de equipes médicas melhorando qualitativamente a prestação do serviço público, pois essa ausência de infraestrutura adequada ocasiona a impossibilidade de acesso ao sistema de saúde na área pública, representando na violação a esse direito humano fundamental e social de segunda dimensão.

O método adotado na consecução será de natureza bibliográfica, quanto ao método de abordagem a ser adotado no seu desenvolvimento será o hipotético dedutivo, tendo pressuposto argumentos gerais (premissa maior) para argumentos particulares (premissa menor); enquanto o procedimento será analítico.

\section{A TEORIA DA FUNÇÃO PROMOCIONAL DO DIREITO DE NOBERTO BOBBIO}

A técnica da facilitação utiliza-se de incentivos que precedem ou acompanham o comportamento que se pretende encorajar, diferindo das sanções positivas propriamente ditas, que se utilizam da concessão de prêmios como recompensa por uma ação desejada já praticada. Como adverte Bobbio, é preciso adequar a teoria geral do direito às transformações da sociedade contemporânea e ao crescimento do Estado Social, a fim de descrever com exatidão a passagem do Estado garantista para o Estado dirigista, e, por conseguinte, a 
transformação do direito como mero instrumento de "controle social" a um mecanismo de direção social.

A análise meramente estrutural (teoria estruturalista) do ordenamento jurídico não é mais suficiente para explicar os fenômenos atuais, devendo, a teoria do direito, ser complementada por uma análise funcional do direito, com destaque para a função promocional, ou seja, a ação que o direito desenvolve pelo instrumento das sanções positivas, destinadas a promover a realização de atos socialmente desejáveis. Grande parte da teoria geral do direito europeu é prisioneira de um conceito de direito que pressupõe a imagem simplista do Estado como organismo que estabelece as regras do jogo e institui um árbitro.

Entre as novas técnicas de controle social presentes no Welfare State ${ }^{3}$, diferentes do Estado Liberal ${ }^{4}$, estão o emprego cada vez maior das técnicas de encorajamento em substituição às técnicas de desencorajamento. Isto põe em crise a teoria da função protetora que considera o direito do ponto de vista exclusivamente de sua função repressiva. A essa teoria tem-se dois pensamentos distintos: A mais clássica, de Christianus Thomassius, afirmava que o direito conquista o seu objetivo (essencialmente protetor) por meio de da emanação de comandos negativos (proibições); e, a mais amplamente utilizada, comum ao positivismo jurídico, a qual se filiam Jhering e Kelsen - os quais afirmam que o direito atinge o próprio objetivo (essencialmente repressivo) através da organização de sanções negativas (direito como aparato coativo).

Nesse aspecto, Bobbio afirma que Jhering, assim como Hegel, distinguia sociedade civil e estado, bem como, a cisão entre a esfera dos interesses econômicos e a dos interesses políticos, e entre a condição do burguês e a do cidadão. Já para Friederich A. Hayek, sugere a ideia de que enquanto o estado liberal clássico se baseava num ordenamento jurídico predominantemente por normas de conduta (normas primárias) o Estado Assistencial

\footnotetext{
${ }^{3}$ Estado do bem-estar (Welfare state), ou Estado assistencial, pode ser definido, à primeira análise, como Estado que garante "tipos mínimos de renda, alimentação, saúde, habitação, educação, assegurados a todo o cidadão, não como caridade, mas como direito político". Os anos 20 e 30 assinalam um grande passo para a constituição do Welfare state. A Primeira Guerra Mundial, como mais tarde a Segunda, permite experimentar a maciça intervenção do Estado, tanto na produção (indústria bélica), como na distribuição (gêneros alimentícios e sanitários). A grande crise de 29 , com as tensões sociais criadas pela inflação e pelo desemprego, provoca em todo o mundo ocidental um forte aumento das despesas públicas para a sustentação do emprego e das condições de vida dos trabalhadores (BOBBIO, 1999, p. 416 - 417)

${ }^{4}$ Liberalismo é um movimento de ideias que passa através de diversos autores diferentes entre si, com Locke, Montesquieu, Kant, Adam Smith, Humboldt, Constant, John Stuart Mill, Tocqueville, para lembrar o nome de autores elevados ao céu dos clássicos. Porém, por mais numerosos que possam ser os aspectos sob os quais se apresenta a doutrina liberal passando de autor a autor, já que é boa regra não multiplicar os entes, considero que, mesmo ao término do discurso que estou fazendo, os aspectos fundamentais são o econômico e o político, e por isso" merecem estar sempre presentes. O liberalismo é, como teoria econômica, fautor da economia de mercado; como teoria política, é fautor do estado que governe o menos possível ou, como se diz hoje, do estado mínimo (isto é, reduzido ao mínimo necessário). (BOBBIO, 1986, p. 114)
} 
projetava-se em um ordenamento jurídico composto por normas de organização secundárias, aquelas pelas quais o estado regula a ação dos próprios órgãos. (BOBBIO, 2007, pp. 10 e 11).

\begin{abstract}
O vertiginoso aumento das normas de organização nos fará abandonar a imagem do direito tradicional com ordenamento protetor-repressivo em direção ao ordenamento com função promocional. Nas constituições pós-liberais, ao lado da função de tutela ou garantia, aparece com maior e mais frequência a função de promover. Entre a afirmação de uma tarefa meramente protetora, que se realiza quase sempre mediante a técnica das medidas negativas, e a afirmação de uma tarefa promocional, que se realiza quase sempre por medidas positivas. Um ordenamento repressivo efetua operações de três tipos e graus, típicos de impedir uma ação não desejada: torná-la impossível, torná-la difícil e torná-la desvantajosa. Ao lado, afirma-se que um ordenamento promocional busca atingir o próprio fim pelas três operações contrárias, buscando tornar a ação desejada, fácil e vantajosa. (BOBBIO, 2007, pp. $14-15)$
\end{abstract}

A definição de desencorajamento e encorajamento é mais ampla do que aquela usualmente oferecida, a qual encerra apenas a terceira forma, na visão de Bobbio, a sanção propriamente dita, nas duas espécies: sanção negativa - Pena; sanção positiva - prêmio. Para desencorajar um comportamento não desejado pode-se tanto ameaçar com uma pena (sanção negativa) quando o comportamento se realizar, ou tornar o comportamento mais penoso. Já nas técnicas de encorajamento, a sanção como recompensa vem depois do comportamento realizado, enquanto a facilitação e o incentivo precedem ou acompanham o comportamento desejado que se pretenda encorajar.

Uma das características mais evidentes do sistema jurídico de um estado assistencial é o aumento das chamadas leis de incentivo ou leis incentivo. Bobbio refere que considerando as medidas de desencorajamento e as de encorajamento de um ponto de vista funcional, o essencial é destacar que as primeiras são utilizadas predominantemente com fulcro na conservação social (manutenção do status quo) e as segundas com o objetivo de mudança. Com as exigências do estado contemporâneo, o direito não se limita mais somente a tutelar ato conforme as próprias normas, mas tende a estimular atos inovadores, sua função deixa de ser apenas protetora e passa a ser também promocional.

As sanções positivas dão vida a uma técnica de estímulo e propulsão a atos considerados socialmente úteis, em lugar da repressão de atos considerados socialmente nocivos. Diferenciando medidas preventivas e sucessivas, Bobbio conceitua as preventivas como aquelas que tendem a promover o comportamento desejado, suscitando uma esperança, ou a impedir o comportamento não desejado, enquanto as sucessivas são as medidas que se seguem ao comportamento, com uma reação favorável quando o comportamento desejado, e desfavorável quando o comportamento é o indesejado (BOBBIO, 2007, p. 26). 
Bobbio afirma que tal qual uma sanção negativa, uma sanção positiva se resolve na superveniência de uma obrigação secundária - lá, no caso de violação e aqui, no caso de cumprimento de uma obrigação primária. Entende-se, assim, que sanção jurídica não é mera coação, coação é, tão-somente, o elemento que garante o cumprimento da sanção. Trata ainda da técnica da facilitação, à qual corresponde, no caso do desencorajamento, a técnica de obstacularização. Entende como facilitação o conjunto de expedientes as quais um grupo social exerce um tipo de controle sobre o comportamento dos membros, não pelo estabelecimento de uma recompensa ou prêmio à ação desejada, mas atuando de modo concomitante visando que sua realização se torne mais fácil ou menos onerosa.

Podem ser distinguidos três graus: medidas de constrição ou preclusão, que visam promover o aparecimento do comportamento desejado ou impedir o não desejado; medidas de facilitação ou de obstacularização, que procuram favorecer a realização de uma conduta desejada ou desfavorecer a prática de uma indesejada; e, medidas de retribuição ou de reparação, que intervêm quando o comportamento já ocorreu visam atribuir consequências agradáveis ao comportamento desejado, desagradáveis ao indesejado. Somente estas últimas são sanções propriamente ditas.

Outro instrumento de deterioração do direito (coativo e sancionador) seria à prevenção, comparando-a a medicina, afirmando que a ciência médica que tenha desenvolvido potencialidades na remoção de doenças é uma sociedade sem hospitais. Ao ressaltar a importância dos surgimentos dessas tendências estamos de encontro à perda da função do direito que consagrou a visão tradicional do direito como elemento essencial, a formação da sociedade civil em contraposição ao estado de natureza, onde um "estado sem direito é um estado que não permite a sobrevivência dos homens".

Para Bobbio a função do direito não é apenas manter a ordem constituída, mas mudala, adaptando-a as mudanças sociais, "o próprio ordenamento jurídico prevê procedimentos destinados à produção de novas normas". O direito pode ser um instrumento adequado para transformar a sociedade? Qual a relação do direito com a mudança social? Para Bobbio o direito quando chega atrasado é um obstáculo a mudanças, quando antecipado ocasiona uma mudança inesperada. Às vezes por mais que um juiz tenha a melhor intenção de fazer justiça, tal fim frequentemente se torna impossível pela própria estrutura das normas jurídicas".

$\mathrm{Na}$ esteira desse raciocínio, o que o direito conseguirá obter em relação tanto à conservação quanto à mudança é obtida por meio do bom funcionamento do aparato coativo. Apoiando-se na força, contribuirá para a perpetuação de uma sociedade fundada sobre relações de força (violência das instituições). Uma das funções do direito é a concepção 
distributiva, a qual Bobbio destaca que seria a função pela qual aqueles que dispõem do instrumento jurídico conferem aos membros sociais (individuais ou grupos de interesse) recursos econômicos e não econômicos de que dispõem. Pois, além da manutenção da ordem e da paz social o direito tem entre suas funções:

A distribuição das possibilidades para a modificação de um ordenamento existente e para o exercício da influência sobre certas decisões governamentais, uma vez que as funções mesmas incluem a distribuição dos bens de consumo, dos impostos, das possibilidades de emprego, da educação, das chances matrimoniais. Justifica Bobbio que em qualquer grupo social, a começar pela família, a função do sistema normativo que o rege não é apenas prevenir e reprimir os comportamentos desviantes ou impedir os surgimentos dos conflitos e facilitar-lhe a composição após seu surgimento, mas também repartir os recursos disponíveis. A função distributiva cresce à medida que faltou a (intervenção) do Estado nas relações econômicas e a distribuição dos recursos.

\section{O DIREITO À SAÚDE NAS CONVENÇÕES INTERNACIONAIS DE DIREITOS HUMANOS: PREVISÕES NORMATIVAS}

No campo da ordem social, bem como, a ordem econômica, adquiriram dimensão jurídica normativa a partir da positivação dos direitos sociais nas constituições mexicana (1917), Constituição alemã de Weimar (1919), a qual influenciou na confecção do titulo sobre a ordem econômica e social da Constituição brasileira de 1934, tendo continuado nas cartas constitucionais posteriores, estando previsto na Constituição Federal de 1988 (Art. 170). De tal modo que, constituem uma extensão da perspectiva do Estado Social de Direito ${ }^{5}$.

Como ensina o professor Silva (2015), “os direitos sociais, no âmbito destas constituições, saíram da ordem social, em regra ligada com a ordem econômica”. Porém, a Constituição de 1988 separou os institutos, trazendo um capítulo (capitulo II do Título II), para os direitos sociais, e, mais adiante, um título especial sobre a ordem social (Título VII). Muito embora haja uma separação na previsão constitucional, não há um distanciamento rígido, como se ambos os direitos distinguissem corpo e alma, sem qualquer ligação.

\footnotetext{
${ }^{5}$ A crise econômica de 1929, consoante referido, bem como os diversos movimentos sociais por melhores condições de trabalho, sem dúvida, influenciaram a promulgação do texto de 1934, abalando, assim, os ideais do liberalismo econômico e da democracia liberal da Constituição de 1891. Por isso é que a doutrina afirma, com tranquilidade, que o texto de 1934 sofreu forte influência da Constituição de Weimar da Alemanha de 1919, evidenciando, portanto, os direitos humanos de $2 .^{a}$ geração ou dimensão e a perspectiva de um Estado social de direito (democracia social). (LENZA, 2016, p. 131).
} 
O Art. 6. ${ }^{\circ}$ elenca a conexão entre ambos os conteúdos quando diz: Art. $6^{\circ}$ São direitos sociais a educação, a saúde, a alimentação, o trabalho, a moradia, o transporte, o lazer, a segurança, a previdência social, a proteção à maternidade e à infância, a assistência aos desamparados, na forma desta Constituição. (Redação atualizada pela Emenda Constitucional $\mathrm{n}^{\circ}$ 90, de 2015). Enquanto direitos fundamentais (alocados no Título II da CF/88), os direitos sociais têm aplicação imediata (art. $5 .^{\circ}, \S 1^{\circ}$ ) e podem ser efetivados, no caso de omissão do legislador, pelas técnicas de controle (o mandado de injunção ou ação direta de inconstitucionalidade por omissão - ADO $)^{6}$.

Conforme as lições de José Afonso da Silva ao conceituar os direitos sociais, o autor define como sendo dimensão dos direitos fundamentais do homem, sendo prestações positivas proporcionadas pelo Estado, direta ou indiretamente, enunciadas em normas constitucionais, que possibilitam melhores condições de vida aos mais fracos, direitos que tendem a realizar a igualização de situações sociais desiguais. São, portanto, direitos que se ligam ao direito de igualdade, valendo como pressupostos do gozo dos direitos individuais na medida em que criam condições de materiais mais propiciais para alcançar a igualdade real, o que, por sua vez, permite a compatibilidade com o exercício concreto da liberdade (SILVA, 2015, p. 287).

Os direitos/ liberdades individuais (do homem), tem como marco histórico as revoluções liberais do século XVIII (Europa e nos Estados Unidos), também numa perspectiva interligada a evolução histórica dos direitos humanos. O papel do Estado na defesa dos direitos de primeira geração é de certo modo, um papel passivo, isto é, consiste na abstenção em violar os direitos humanos, ou seja, as prestações negativas, porém quanto ativo, há de se exigir ações do Estado para garantia da segurança pública, administração da justiça, liberdade, igualdade, propriedade. Em relação à segunda geração de direitos humanos representa a modificação da função estatal, exigindo-lhe um vigoroso papel ativo, além do mero fiscal das regras jurídicas. Sobre esse aspecto,

A segunda geração de direitos humanos representa a modificação do papel do
Estado, exigindo-lhe um vigoroso papel ativo, além do mero fiscal das regras
jurídicas. Esse papel ativo, embora indispensável para proteger os direitos de
primeira geração, era visto anteriormente com desconfiança, por ser considerado
uma ameaça aos direitos do indivíduo. Contudo, sob a influência das doutrinas
socialistas, constatou-se que a inserção formal de liberdade e igualdade em

${ }^{6}$ A definição de "direito individual" (referente ao conteúdo de afetação somente a interesses de um indivíduo) permite que sejam identificados tais direitos em toda a Constituição, inclusive nos chamados direitos políticos (por exemplo, o direito de voto) e nos direitos sociais (direito à saúde e à educação tem claro perfil de atendimento à pretensão individual). Além disso, a restrição do termo "direitos individuais" aos direitos que constam somente do art. $5^{\circ}$ poderia produzir interpretações restritas quanto ao conjunto de direitos protegido pela imutabilidade do art. 60, $\S 4^{\circ}$, IV, e quanto ao alcance do art. $5^{\circ}, \S 1^{\circ}$ (aplicação imediata). (RAMOS, 2017 , p. 63) 
declarações de direitos não garantiam a sua efetiva concretização, o que gerou movimentos sociais de reivindicação de um papel ativo do Estado para assegurar uma condição material mínima de sobrevivência. Os direitos sociais são também titularizados pelo indivíduo e oponíveis ao Estado. São reconhecidos o direito à saúde, educação, previdência social, habitação, entre outros, que demandam prestações positivas do Estado para seu atendimento e são denominados direitos de igualdade por garantirem, justamente às camadas mais miseráveis da sociedade, a concretização das liberdades abstratas reconhecidas nas primeiras declarações de direitos. (RAMOS, 2017, p. 54).

Foram os movimentos sociais do século XIX (no início do século XX) ${ }^{7}$, o surgimento da segunda geração/dimensão dos direitos fundamentais, responsável pela gradual passagem do Estado liberal (individualista/absenteísta) para o Estado social, focado na proteção dos hipossuficientes, com a finalidade de assegurar a igualdade material entre os homens (não apenas formal, ou seja, prevista em lei, como se assegurava no Estado liberal). Os direitos fundamentais de segunda geração correspondem aos direitos de participação, sendo realizado por intermédio da execução de políticas e serviços públicos, exigindo do Estado prestações sociais $^{8}$, tais como saúde, educação, trabalho, habitação, previdência social, assistência social, denominados direitos positivos, direitos do bem- estar.

Inclusive, a existência de precedentes jurisprudenciais no Supremo Tribunal Federal STF, que autorizam a intervenção do Poder Judiciário, exigindo do Poder Executivo a adoção de providências administrativas que visem a melhoria da qualidade da prestação do serviço de saúde pública. Houve a ponderação entre os princípios do mínimo existencial e da reserva do possível, tendo sido decidido que, no caso do direito à saúde, a intervenção judicial é possível, pois não há usurpação da separação de poderes, mas tão somente determinação judicial para

\footnotetext{
${ }^{7} \mathrm{Na}$ contextualização histórica dos direitos de "segunda dimensão" está mais do nunca presente o surto do processo de industrialização e os graves impasses socioeconômicos que varreram a sociedade ocidental entre a segunda metade do século XIX e as primeiras décadas do século XX. O capitalismo concorrencial evolui para a dinâmica financeira e monopolista, e a crise do modelo liberal de Estado possibilita o nascimento do Estado do Bem-Estar Social, que passa a arbitrar as relações entre o capital e o trabalho. O período ainda registra o desenvolvimento das correntes socialistas, anarquistas e reformistas. Não menos importante para os avanços sociais são: a posição da Igreja Católica com sua doutrina social (a Encíclica Rerum Novarum, de Leão XIII, 1891); os efeitos políticos das Revoluções Mexicana (1911) e Russa (1917); os impactos econômicos do keynesianismo e o intervencionismo estatal do New Deal. Cria-se a Organização Internacional do Trabalho (1919); o movimento sindical ganha força internacional; a socialização alcança a política e o Direito (nascem o Direito do Trabalho e o Direito Sindical). As principais fontes legais institucionalizadas estão positivadas na Constituição Mexicana de 1917, na Constituição Alemã de Weimar de 1919, na Constituição Espanhola de 1931 e no Texto Constitucional de 1934 do Brasil. (WOLKMER, 2002, p. 15)

${ }^{8}$ Los derechos a prestaciones en sentido estricto son derechos del indivíduo frente al Estado a algo que — si el indivíduo poseyera medios financieros suficientes y si encontrase en el mercado una oferta suficiente- podría obtenerlo también de particulares. Cuando se habla de derechos sociales fundamentales, por ejemplo. del derecho a la previsión, al trabajo, la vivienda y la educación, se hace primariamente referencia a derechos a prestaciones en sentido estricto. (ALEXY, 1997, p. 482). Os direitos de benefícios no sentido estrito são os direitos do indivíduo em face do estado a algo que - se o indivíduo possuísse meios financeiros suficientes e se o mercado tivesse suprimento suficiente — ele também poderia obtê-lo de indivíduos. Quando se trata de direitos sociais fundamentais, por exemplo. Do direito à Previdência, ao trabalho, à habitação e à educação, é essencialmente referida a direitos de benefícios em sentido estrito ( Livre tradução do autor).
} 
que o "Poder Executivo cumpra políticas públicas previamente estabelecidas (RE 642.536AgR, Rel. Min. Luiz Fux, julgamento em 5-2-2013, Primeira Turma, DJE de 27-2-2013).

De acordo com o critério adotado pelo professor Ingo Sarlet, o termo "direitos fundamentais" se aplica àqueles direitos (atribuídos à pessoa humana) reconhecidos e positivados na esfera do direito constitucional positivo de determinado Estado, ao passo que a expressão "direitos humanos" guarda relação com os documentos no âmbito do direito internacional, por referir-se àquelas posições jurídicas que se reconhecem ao ser humano como tal, independentemente de sua vinculação com determinada ordem constitucional, e que, portanto, aspiram à validade universal, para todos os povos e em todos os lugares, revelando um caráter supranacional (internacional) e universal. (SARLET, 2010, p. 314).

Na mesma linha, para Sidney Guerra, os direitos fundamentais ou direitos humanos, direitos civis, direitos individuais, liberdades públicas são formas diferentes de expressar a mesma realidade. Considerando a fórmula direitos humanos para aqueles positivados em nível internacional e os direitos fundamentais para os direitos humanos positivados em nível interno, isto é, garantidos pelo ordenamento jurídico estatal. $\mathrm{O}$ autor salienta que as liberdades públicas, direitos humanos são as prerrogativas que tem o indivíduo em face do Estado; as liberdades públicas serão componentes mínimos do Estado Constitucional ou do Estado de Direito (GUERRA, 2012, pp. 96 - 98).

No campo do direito internacional, vários instrumentos jurídicos e normativos reconheceram direito do ser humano à saúde, conforme a Compilação de Instrumentos Internacionais de Direitos Humanos, da Provedoria de Justiça e Direitos Humanos do Timor Leste (2009, p. 150). Vale ressaltar, os principais Tratados e Convenções Internacionais:

1) A Declaração Universal dos Direitos Humanos (1948), em seu Artigo 25. 1, prevê: Todo ser humano tem direito a um padrão de vida capaz de assegurar-lhe, e a sua família, saúde e bem-estar, inclusive alimentação, vestuário, habitação, cuidados médicos e os serviços sociais indispensáveis, e direito à segurança em caso de desemprego, doença, invalidez, viuvez, velhice ou outros casos de perda dos meios de subsistência em circunstâncias fora de seu controle.

2) O Pacto Internacional sobre os Direitos Económicos, Sociais e Culturais o direito de toda pessoa desfrutar do mais elevado nível possível de saúde física e mental também é assegurado no Pacto (art. 12), devendo o Estado adotar as medidas necessárias para promover a redução da mortalidade infantil e do índice de natimortos, bem como o desenvolvimento sadio das crianças; a melhoria da higiene do trabalho e do meio ambiente; a prevenção e o tratamento de doenças epidêmicas, endêmicas, profissionais e outras, bem como a luta contra essas doenças e a criação de condições que assegurem a todos assistência médica e serviços médicos em caso de doença.

3) No artigo $5^{\circ}$, alínea e, IV da Convenção Internacional Sobre a Eliminação de Todas as Formas de Discriminação Racial (1965); no artigo $11 .^{\circ}$, n. $^{\circ} 1$ alínea f, e no artigo 12.o da Convenção Sobre a Eliminação de Todas as Formas de Discriminação Contra as Mulheres (1979) e no artigo 24. da Convenção sobre os Direitos da Criança (1989). 
4) Vários instrumentos de direitos humanos também reconhecem o direito à saúde, como a Carta Social Europeia (1961) na sua forma revista artigo $11 .^{\circ}$, a Carta Africana de Direitos Humanos e dos Povos (1981), no (artigo 16 e o Protocolo Adicional à Convenção Americana sobre Direitos Humanos em Matéria de Direitos Económicos, Sociais e Culturais (1988), no artigo $10^{\circ}$.

De modo que, o direito à saúde possui ligação com a concretização de outros direitos humanos e, por consequência, depende desses direitos, que se expressam na Convenção Internacional de Direitos Humanos da ONU (1948), de forma objetiva ao direito à alimentação, alojamento, trabalho, à educação, à dignidade humana, à vida, a não discriminação, à igualdade, à proibição da tortura, à privacidade, ao acesso à informação e às liberdades de associação, reunião e movimento. Estes direitos e liberdades, dentre outros, associam-se e suplementam o direito à saúde. Para a ONU:

Ao elaborar o artigo 12.o do Pacto, a Terceira Comissão da Assembleia Geral das Nações Unidas não adoptou a definição de saúde que figura no preâmbulo da Constituição da OMS, que conceitualiza a saúde como "um estado de completo bem-estar físico, mental e social, e não consiste apenas na ausência de doença ou de enfermidade". No entanto, a referência do artigo 12.o, $\mathrm{n}^{\circ} 1$ do Pacto, "do melhor estado de saúde física e mental possível de atingir", não se limita ao direito aos cuidados de saúde. Pelo contrário, o historial da elaboração e da redação expressa no artigo 12.o, $\mathrm{n}^{\mathrm{o}} 2$ reconhece que o direito à saúde engloba uma vasta gama de fatores socioeconómicos que promovem as condições nas quais as pessoas podem levar uma vida sã e torna esse direito extensivo aos fatores determinantes básicos da saúde, como alimentação, nutrição, alojamento, acesso a água limpa e potável e condições sanitárias adequadas, condições de trabalho seguras e saudáveis e um meio ambiente são. (Provedoria dos Direitos Humanos e Justiça, 2009, p. 156).

$\mathrm{O}$ artigo $12 .^{\circ}, \mathrm{n}^{\mathrm{o}} 1$ do PIDSC define o direito à saúde, reconhecendo o direito de toda pessoa de desfrutar o mais elevado nível possível de saúde física e mental. Enquanto o artigo 12. ${ }^{\circ}$, n. ${ }^{\circ}$ 2, com o fim precípuo de assegurar o pleno exercício desse direito incluirão as medidas que se façam necessárias para assegurar a diminuição da mortinatalidade e da mortalidade infantil, bem como o desenvolvimento é das crianças, a melhoria de todos os aspectos de higiene do trabalho e do meio ambiente, a prevenção e o tratamento das doenças epidêmicas, endêmicas, profissionais e outras, bem como a luta contra essas doenças, a criação de condições que assegurem a todos assistência médica e serviços médicos em caso de enfermidade.

O Comité interpreta o direito à saúde, definido no artigo $12^{\circ}, \mathrm{n}^{\circ} 1$, como um direito inclusivo que englobaria não apenas os cuidados de saúde oportunos e apropriados, como também os elementos definitivos e indiretos a saúde, tais como, o acesso à água potável, condições sanitárias adequadas, um fornecimento adequado de alimentos e nutrição adequada, um alojamento, condições de trabalho, do meio ambiente saudável, acesso à educação/ informação, assim como a saúde sexual e reprodutiva. Assim, os fatores genéticos, a 
propensão individual à doença e a adoção de estilos de vida doentios ou perigosos podem desempenhar um papel importante no que respeita a saúde do ser humano ${ }^{9}$. Sendo assim,

\begin{abstract}
A indivisibilidade consiste no reconhecimento de que todos os direitos humanos possuem a mesma proteção jurídica, uma vez que são essenciais para uma vida digna. A indivisibilidade possui duas facetas. A primeira implica reconhecer que o direito protegido apresenta uma unidade incindível em si. A segunda faceta, mais conhecida, assegura que não é possível proteger apenas alguns dos direitos humanos reconhecidos. O objetivo do reconhecimento da indivisibilidade é exigir que o Estado também invista tal qual investe na promoção dos direitos de primeira geração - nos direitos sociais, zelando pelo chamado mínimo existencial, ou seja, condições materiais mínimas de sobrevivência digna do indivíduo. A indivisibilidade também exige o combate tanto às violações maciças e graves de direitos considerados de primeira geração (direito à vida, integridade física, liberdade de expressão, entre outros) quanto aos direitos de segunda geração (direitos sociais, como o direito à saúde, educação, trabalho, previdência social etc.). (RAMOS, 2017, p. 94).
\end{abstract}

A interdependência ou inter-relação consiste no reconhecimento de que todos os direitos humanos contribuem para a realização da dignidade humana, interagindo para a satisfação das necessidades essenciais do indivíduo, o que exige, novamente, a atenção integral a todos os direitos humanos, sem exclusão. O conteúdo de um direito pode se vincular ao conteúdo de outro, demonstrando a interação e a complementaridade entre eles, bem como que certos direitos são desdobramentos de outros.

Isto porque, diversamente de outros instrumentos internacionais, os tratados internacionais de direitos humanos não objetivam estabelecer o equilíbrio de interesses entre os Estados, mas sim garantir o exercício de direitos e liberdades fundamentais aos indivíduos. Atente-se que o Direito Internacional dos Direitos Humanos (DIDH), com seus inúmeros instrumentos, não pretende substituir o sistema nacional. Em sentido contrário, situa-se como direito subsidiário/suplementar ao direito nacional, no sentido de permitir sejam superadas suas omissões e deficiências. No sistema internacional de proteção dos direitos humanos, o Estado tem a responsabilidade primária pela proteção desses direitos, ao passo que a comunidade internacional tem a responsabilidade subsidiária. (PIOVESAN, 2012, p. 241).

O reconhecimento de que todos os direitos humanos possuem a mesma proteção jurídica, são essenciais para uma vida digna, tem duas peculiaridades: implica reconhecer que o direito protegido apresenta uma unidade incindível em si; assegura que não é possível proteger apenas alguns dos direitos humanos reconhecidos. Quanto ao objetivo de

\footnotetext{
${ }^{9} \mathrm{O}$ direito humano à saúde apresenta um vasto e complexo conjunto de questões relacionadas porque a saúde e o bem-estar estão de forma intrínseca conexos a todas as etapas do mundo da vida. Nos instrumentos internacionais de direitos humanos encontram direitos específicos relacionados com a saúde. Essencialmente, todos os direitos humanos são interdependentes, indivisíveis, interrelacionados. Assim, a realização dos direitos humanos e a negligência relativamente aos mesmos ou a sua violação é relevante para um conjunto de direitos humanos e não para, apenas, um direito isolado (Disponível em http.www.fd.uc.pt/igc/manual/pdfs/A.pdf. Data de Acesso 04.10.2017).
} 
reconhecimento, consiste no exigir que o Estado também invista nos direitos sociais, zelando pelo mínimo existencial, ou seja, condições materiais mínimas de sobrevivência digna do indivíduo; exigir o combate tanto às violações maciças e graves de direitos considerados de primeira geração quanto aos direitos de segunda geração.

Assim, o direito à saúde está intimamente conexo à realização de outros direitos humanos e dependentes desses mesmos direitos, previstos na Carta Internacional dos Direitos Humanos, tais como, o direito à alimentação, ao alojamento, ao trabalho, à educação, à dignidade humana, à vida, à indiscriminação, à igualdade, à proibição da tortura, à privacidade, ao acesso à informação e às liberdades de associação e reunião. Estes e outros direitos e liberdades abordam componentes integrantes do direito à saúde. No próximo ponto, será abordada a relação entre a corrupção e a violação do direito humano a saúde.

\section{A CORRUPÇÃO E A VIOLAÇÃO DO DIREITO HUMANO A SAÚDE}

No âmbito do direito interno, o direito à saúde é um direito de todos, constituindo um dever do Estado sua efetivação no art. 196 da Constituição Federal, ao elencar que a saúde é direito de todos e dever do Estado, garantido mediante políticas sociais e econômicas que visem à redução do risco de doença e de outros agravos e ao acesso universal e igualitário às ações e serviços para sua promoção, proteção e recuperação. Como ensina Ramos (2017, p. 851), "realmente o Estado deve promover políticas sociais e econômicas destinadas a possibilitar o acesso universal igualitário às ações e serviços para a promoção, proteção e recuperação da saúde”.

Nesse sentido, a noção de direito assim como a de saúde no Estado contemporâneo torna necessário uma compreensão ampla do meio ambiente em que será realizado e concretizado o direito à saúde. É preciso que o legislador ordinário, o administrador e o Estado - juiz possam conduzir-se em meio a tantas variantes sociais, políticas, econômicas e culturais que participam da definição do estado de saúde das pessoas. São normas jurídicas que deverão revelar o sentido exato de saúde albergado por determinada comunidade (DALLARI, 2009, p. 14)

Pela ótica do direito constitucional, é o que se pode chamar de uma das dimensões do mínimo existencial à dignidade da vida humana, inclui a saúde, enquanto princípio fundante do sistema jurídico, eis que a vida humana digna reflete e se conecta ao fator político, econômico, social e jurídico ao mesmo tempo em que, na condição de princípio fundamental, 
opera sobre atos estatais e privados imperativamente. Por essa razão, todas as normas jurídicas deverão ter como norte de interpretação a conformidade com esse princípio; as normas jurídicas infraconstitucionais, em desacordo com a constituição e seus princípios fundantes, em especial, a dignidade da vida humana, serão consideradas inválidas (LEAL, 2008, p. 51).

Como ensina Ingo Sarlet, os direitos sociais também residem na proteção da dignidade da pessoa humana. A garantia de uma existência digna tem como elo a pobreza, a exclusão social e a violação dos direitos humanos não sendo viável desconsiderar a conexão e a vinculação de forma direta de todos os direitos sociais consagrados no Art. $6 .^{\circ}$ da Constituição, ou mesmo declinar, quanto à importância desses direitos de segunda geração para o gozo efetivo de uma vida digna, o que, outrora, não aparta a averiguação de que as condições de vida e os requisitos elementares constituem variantes de acordo com cada sociedade em uma determinada época. (SARLET, 2001, p. 94).

Por outro lado, o debate sobre o tema da corrupção na contemporaneidade, tem se focado no campo da economia e da esfera jurídica; porém o problema é quando se tenta enquadrar o tema apenas na esfera econômica, acabam restringido outras abordagens acerca de suas causas, consequências e tratamentos em razão da intensidade de tais violações e, muitas vezes, em razão da impossibilidade de amoldar a corrupção a práticas não monetárias (por exemplo, o plágio acadêmico); logo, é importante observar que o fenômeno corruptivo destrói os valores fundamentais da dignidade humana e da igualdade, tornando impossível garantir os direitos à vida e à dignidade pessoal (LEAL, 2013, pp. 15 - 16).

Para fins do presente trabalho, cabe a seguinte indagação: Quando a corrupção pode violar o direito a saúde? O Conselho Internacional de Políticas de Direitos Humanos, responde a esse questionamento tendo como premissa que o direito da saúde exige a atenção médica e, além disso, tem como fatores determinantes e subjacentes, a questão da agua potável, das medidas sanitárias, do seguro de alimentos, da nutrição, da habitação, da saúde ocupacional, da saúde ambiental e o acesso a informação relacionada com a saúde.

Numa visão sociológica, Schilling salienta o caráter da generalização ou institucionalização. Contudo, ainda que na sua compreensão fenomênica a corrupção seja tida generalizada ou institucionalizada, espalhando-se por uma ampla gama de setores da sociedade, ainda assim estaria localizada em determinado setor privilegiado, em que ocorre a troca entre aqueles que em uma dada sociedade detém o exercício de influência e a capacidade determinada pela posse do poder decisório, no campo político, ou poder 
econômico, junto ao mercado (SCHILLING, 1998, p. 22). Segundo Relatório da

Transparência Internacional Global Corruption Report:

A comunidade de direitos humanos precisa prestar ainda mais atenção à corrupção. O mais alto padrão possível de saúde é um dos direitos fundamentais de cada humano, incorporado no artigo 12 do Pacto Internacional de Direitos Econômicos, Direitos sociais e culturais. Corrupção - ao lado da pobreza, desigualdade, conflito civil, discriminação e violência - é uma questão importante que não foi abordada adequadamente no âmbito desses direitos básicos. Isso leva à distorção dos gastos com a saúde prioridades e lixiviação dos orçamentos de saúde, resultando na negligência de doenças e as comunidades afetadas por eles; Isso também significa que as pessoas pobres geralmente decidem contra o tratamento salva-vidas, porque eles não podem pagar as taxas cobradas pela saúde serviços que devem ser gratuitos. A corrupção no setor da saúde afeta pessoas em todo o mundo, como ensaios apresentado no Global Corruption Report 2006 reflete. Dinheiro que deve ser gasto no alívio da pobreza e da doença acaba em bolsas privadas. Nesse caminho, A corrupção literalmente viola os direitos humanos, à medida que as pessoas são negadas os cuidados que seus. Os governos são obrigados a fornecer. ${ }^{10}$ (2006, p. $15)^{11}$.

O direito da saúde exige a atenção médica e também de fatores determinantes, tais como, agua potável, as medidas sanitárias, o seguro de alimentos, a nutrição, a habitação, a saúde ocupacional, a saúde ambiental e o acesso à informação relacionada com a saúde. Outro componente essencial este direito, no qual o Estado deve garantir em quaisquer circunstâncias, independentemente dos recursos disponíveis, o acesso ao cuidado da saúde materna e infantil, que inclui a planejamento familiar, a imunização contra as principais doenças infecciosas, o tratamento apropriado de doenças, a instalação adequada de água potável, a higiene básica e a erradicação ameaças ambientais graves contra a saúde.

\footnotetext{
${ }^{10} \mathrm{~A}$ comunidade de direitos humanos precisa prestar ainda mais atenção à corrupção. O maior padrão de saúde atingível é um dos direitos fundamentais de cada ser humano, incorporado no artigo 12 do Pacto Internacional sobre os direitos econômicos, sociais e culturais. A corrupção - ao lado da pobreza, da desigualdade, do conflito civil, da discriminação e da violência - é uma questão importante que não tem sido adequadamente abordada no âmbito desses direitos básicos. Conduz à inclinação das prioridades de despesa em saúde e à lixiviação dos Orçamentos sanitários, resultando na negligência das doenças e das comunidades afectadas por elas; isso também significa que as pessoas pobres muitas vezes decidem contra o tratamento de poupança de vida, porque eles não podem pagar as taxas cobradas pelos serviços de saúde que devem ser livres. A corrupção no setor da saúde afeta pessoas de todo o mundo, já que as mesmas apresentadas no relatório global de corrupção 2006 refletem. $\mathrm{O}$ dinheiro que deve ser gasto em aliviar a pobreza e a doença termina acima preferivelmente em bolsos confidenciais. Dessa forma, a corrupção viola literalmente os direitos humanos, pois as pessoas negam o cuidado que seus (Livre tradução dos autores).

${ }^{11}$ The human rights community needs to pay even more attention to corruption. The highest attainable standard of health is one of the fundamental rights of every human being, incorporated in article 12 of the International Covenant on Economic, Social and Cultural Rights. Corruption - alongside poverty, inequity, civil conflict, discrimination and violence - is a major issue that has not been adequately addressed within the framework of these basic rights. It leads to the skewing of health spending priorities and the leaching of health budgets, resulting in the neglect of diseases and those communities affected by them; it also means that poor people often decide against life-saving treatment, because they cannot afford the fees charged for health services that should be free. Corruption in the health sector affects people all over the world, as the essas featured in the Global Corruption Report 2006 reflect. Money that should be spent on alleviating poverty and illness ends up instead in private pockets. In this way, corruption literally violates human rights, as people are denied the care that their.
} 
De modo que, conforme o Relatório do Comitê de Direitos Econômicos, Sociais e Culturais (2009): O direito à saúde está incluído em vários tratados de direitos humanos. De uma forma muito proeminente, o artigo 12 do ICESCR estabelece o "direito de todos a desfrutar do mais alto nível possível de saúde física e mental", definido como o "direito de desfrutar de uma variedade de meios, bens, serviços e condições necessárias para a Plena eficácia do mais elevado nível de saúde possível. " Embora o conteúdo desta afirmação é extenso, não implica que as pessoas têm o direito de ser saudável ${ }^{12}$.

O direito à saúde está expresso em seu artigo 12. A palavra saúde se origina do latim salute, que significa "salvação, conservação da vida, cura, bem-estar" e, preservando este sentido, o conceito de saúde, segundo definição apresentada pela Organização Mundial de Saúde, é um estado de completo bem-estar físico, mental e social e não apenas a ausência da doença ou enfermidade. Fato humano decorrente do funcionamento da biologia humana, a saúde se insere, pois, como direito humano no regramento jurídico da sociedade como um direito social. Dessa forma, o direito à saúde foi trazido à ordem internacional de proteção aos direitos humanos como direito social e dever de todo Estado Parte garantir a qualquer ser humano o direito a ser saudável, com exemplos de medidas que os Estados devem adotar para garantir plenamente esse direito. (GREGORI, Et al. 2013, p. 202)

Essa obrigação positiva, prevista PDESC da ONU (artigo 12), e em outras
resoluções específicas da Organização Mundial de Saúde e da Organização
Internacional do Trabalho (OIT), relaciona o direito à vida com o direito a um
padrão de vida adequado, reconhecendo o direito à saúde, em sua dimensão ampla,
simultaneamente como natureza de direito individual (básico e fundamental), pois
exige a proteção da integridade física, mental e da dignidade do indivíduo; porém, é
social, eis que impõe ao Estado e à sociedade a responsabilidade coletiva pela
proteção da saúde dos cidadãos, pela prevenção e pelo tratamento de doenças. O
direito à saúde, assim entendido, configura uma ilustração da indivisibilidade e da
inter-relação de todos os direitos humanos, exatamente como ocorre com o direito à
vida. (CANÇADO TRINDADE, Et al, 2003, p. 183).

Vale citar:

Que o âmbito do direito à saúde se manifesta de forma mais contundente a vinculação do seu respectivo objeto, em sua dimensão positiva, tratando de prestações de cunho material (assistência médica, hospitalar etc.) com o direito à vida e o princípio da dignidade da pessoa humana. A despeito do reconhecimento de alguns efeitos decorrentes desse princípio, ainda que após a morte, a dignidade atribuída ao ser humano é essencialmente da pessoa humana viva. $\mathrm{O}$ direito à vida em sua conexão verifica-se o direito à saúde, constituindo, além disso, pré-condição da própria dignidade da pessoa humana. Para além da vinculação com o direito à

\footnotetext{
$12 \mathrm{O}$ direito à saúde está incluído em vários tratados de direitos humanos. De uma forma muito proeminente, o artigo 12 do ICESCR estabelece o "direito de todos a desfrutar do mais alto nível possível de saúde física e mental", definido como o "direito de desfrutar de uma variedade de meios, bens, serviços e condições necessárias para a Plena eficácia do mais elevado nível de saúde possível. " Embora o conteúdo desta afirmação é extenso, não implica que as pessoas têm o direito de ser saudável (Livre tradução dos autores).
} 
vida, o direito à saúde (em sentido amplo), encontra-se ligado à proteção da integridade física, corporal e psicológica do ser humano (SARLET, 2015, p. 655).

Com as exigências do estado contemporâneo, o direito não se limita mais somente a tutela de atos conforme as próprias normas, mas tende a estimular atos inovadores, sua função deixa de ser apenas protetora e passa a ser também promocional. As sanções positivas dão vida a uma técnica de estímulo e propulsão a atos considerados socialmente úteis, em lugar da repressão de atos considerados socialmente nocivos. (BOBBIO, 2007, p. 24).

Diferenciando medidas preventivas e sucessivas, Bobbio conceitua as preventivas como aquelas que tendem a promover o comportamento desejado, suscitando uma esperança, ou a impedir o comportamento não desejado, enquanto as sucessivas são as medidas que se seguem ao comportamento, com uma reação favorável quando o comportamento desejado, e desfavorável quando o comportamento é o indesejado.

O autor afirma que tal qual uma sanção negativa, uma sanção positiva se resolve na superveniência de uma obrigação secundária, no caso de violação e aqui, no caso de supercumprimento de uma obrigação primária. Entende-se, assim, que sanção jurídica não é mera coação, coação é, tão-somente, o elemento que garante o cumprimento da sanção. Adotando a perspectiva do jurista Italiano, temos que, no caso do Direito a Saúde, a uma prestação positiva do Estado, como uma obrigação primária, a qual o seu descumprimento acarreta consequências a demais direitos, ou seja, a obrigação secundária tais como, a igualdade, a dignidade da pessoa humana, a não discriminação, o direito a vida, a integridade física e biológica, a violência.

Para ele o direito apresenta uma função positiva, por exemplo, a função positiva do parlamento é constatar o seu mau funcionamento, que pode consistir em uma alteração, perversão ou corrupção de qualquer uma de suas funções. A disfunção representa sua função negativa, pois um instituto com funcionalidade positiva pode funcionar mal, sem que, com isso, sua função se torne negativa, assim como um instituto de funcionalidade negativa pode funcionar bem sem que sua função se torne positiva. A função negativa (disfunção) seria a patologia da função. (BOBBIO, 2007, p. 93).

Por outro lado, e claro que, a corrupção também pode atingir Direitos Fundamentais pela via dos comportamentos corruptivos de alguns cidadãos - evidenciando, por certo, a falha estatal de evitar isso, como quando alguém paga suborno para obtenção de determinado tratamento médico-hospitalar, ou paga suborno para conseguir vaga escolar, condutas essas que estão a violar o sistema de ensino e de saúde existente. E até indiretamente, como quando autoridades estatais permitem, pela via do suborno, que sejam comercializados resíduos 
tóxicos e depositados sem as cautelas devidas em áreas de densidade demográfica significativa, gerando as pessoas destas localidades danos à saúde ao longo do tempo. (LEAL, 2013, p. 34).

Para o Conselho Internacional de Políticas de Direitos Humanos e o Instituto Tecnológico de Estudos Superiores de Monterrey (México, 2009), o ponto central do direito a saúde, quanto aos seus principais elementos do direito à saúde podem ser encontrados no Comentário Geral $\mathrm{n}^{\circ} 14$ do CDESC (Pacto Internacional sobre os Direitos Econômicos, Sociais e Culturais); as instalações, bens e serviços, programas, devem estar disponíveis em quantidades suficientes, tendo os Estados a obrigação legal de garantir que a disponibilidade de bens e serviços de saúde não seja atingida por atos de corrupção. Sendo assim,

\begin{abstract}
Os principais elementos do direito à saúde encontram-se no comentário geral $\mathrm{n}^{\circ} 14$ do CESCR. Instalações, bens e serviços, bem como programas, devem estar disponíveis em quantidades suficientes. Por conseguinte, os Estados necessitam de assegurar que a disponibilidade de bens e serviços de saúde não seja afectada por actos de corrupção que, no sector da saúde, possam ter consequências mortais. As instalações de saúde, bens e serviços devem ser acessíveis a todas as pessoas sem discriminação. A acessibilidade tem quatro dimensões sobrepostas. Nãodiscriminação: as instalações de saúde, bens e serviços devem estar dentro do alcance físico, o que é apropriado para todas as pessoas, incluindo grupos vulneráveis ou marginalizados. A corrupção no setor da saúde também pode levar à discriminação direta quando os provedores e profissionais tratam os pacientes de forma diferente, com base em seus rendimentos ou relacionamentos pessoais com a equipe médica. Acesso físico: os centros de saúde, bens e serviços devem ter o escopo físico segurado para todas as camadas da população, incluindo grupos vulneráveis ou marginalizados. A corrupção no setor da saúde pode levar a decisões desfavoráveis a uma comunidade ${ }^{13}$ (ICHRP, 2009, p. 59)
\end{abstract}

Para o relatório os bens e serviços são importantes para não haver discriminação; de igual modo, a acessibilidade a qual possui quatro dimensões medulares, tais como, a não discriminação, as instalações, a corrupção, que também pode gerar a discriminação e a decisão não favoráveis a uma determinada comunidade. Isso porque, a medida os serviços de saúde não estão disponíveis aos grupos vulneráveis em razão do acesso econômico, poderão dar ensejo ao surgimento de atos de corrupção. Por exemplo, quando funcionários do setor de

\footnotetext{
${ }^{13}$ Los elementos medulares del derecho a la salud se encuentran en la Observación General No. 14 del CDESC. Las instalaciones, los bienes y los servicios, así como los programas, deben estar disponibles en cantidades suficientes. Por lo tanto, los Estados necesitan asegurar que la disponibilidad de bienes y servicios de salud no se afecte por los actos de corrupción que, em el sector de la salud, pueden tener consecuencias mortales. Las instalaciones, bienes y servicios de salud deben ser accesibles para todas las personas sin discriminación. La accesibilidad tiene cuatro dimensiones que se superponen. La no-discriminación: las instalaciones, bienes y servicios de salud deben estar al alcance físico, que resulte apropiado para todas las per sonas, incluyendo a los grupos vulnerables o marginados. La corrupción en el sector de la salud puede conducir también a la discriminación directa cuando los proveedores y profesionales tratan a los pacientes en forma diferente, basados en sus ingresos o en sus relaciones personales con el equipo médico. El acceso físico: los centros, bienes y servicios de salud deben tener el alcance físico asegurado para todas las capas de la población, incluso de los grupos vulnerables o marginados. La corrupción en el sector de la salud puede conducir a decisiones que sean desfavorables a una comunidade (ICHRP, 2009, p. 59).
} 
saúde passam a exigir pagamentos, realizando a venda de medicamentos fornecidos gratuitamente por indústrias farmacêuticas, bem como, as exigências de pagamentos informais em troca de tratamentos.

Este último sentido da corrupção como um obstáculo ao exercício dos direitos através da extorsão, existem dois exemplos que permitem desenhe a situação referida em relação à DESC, em particular o direito à alimentação e à saúde. Uma das bordas do referido caso Tibi vs. Ecuador apontou para a existência de um "mercado de direitos", no qual os internos da penitenciária, El Litoral tiveram que pagar todas as "vantagens", que incluíam direitos e serviços básicos. O Tribunal tomou como provado que a vítima tinha que pagar por sua comida por pelo menos os 45 dias que ele passou na célula comum conhecida como "quarentena" 179, que costumava intimidar os presos para que pudessem acessar a extorsão (ROJAS, 2014, p. 164)

Como pode ser visto, o Tribunal entendeu que, em certas circunstâncias, os direitos à alimentação e à saúde estão intimamente ligados à integridade pessoal e à vida (dignos), de modo que uma violação do primeiro pode envolver a violação deste último. No entanto, ele não aludiu a esses direitos diretamente. Isso se justifica na limitada jurisdição do Tribunal em matéria de Direitos Econômicos, sociais e culturais (DESC), embora se possa esperar uma interpretação evolutiva dos instrumentos do sistema interamericano cubra mais frontalmente a relação entre esses direitos, o princípio da igualdade e a não discriminação e a corrupção.

Os recursos perdidos com a corrupção na área de saúde poderiam ser usados para
comprar medicamentos, equipar hospitais, contratar equipes médicas, enfim ampliar
qualitativamente o serviço público propriamente dito, pois a ausência de
infraestrutura adequada neste campo implica a negativa de acesso ao sistema de
saúde pública, o que representa violação direta a Direito Fundamental. Pesquisas
recentes do Fundo Monetário Internacional envolvendo 71 (setenta e um) países
Ocidentais têm indicado que os que possuem os maiores indicadores de corrupção
sistemática também têm as maiores taxas de mortalidade infantil, evidenciando
políticas públicas baixíssimas de tratamento preventivo e curativo de gestantes e
crianças. De igual sorte o Comitê dos Direitos Econômicos, Sociais e Culturais da
União Europeia tem identificado a omissão e falhas de regulação nas atividades
individuais, de grupos ou corporações, bem como falhas na proteção dos
consumidores em face de práticas detrimentosas de saúde (LEAL, 2013, p. 103).

Em vários outros serviços da Administração Pública se podem sentir os efeitos da corrupção, como no Direito à Saúde, por exemplo, entendido de forma ampla, incluindo todos os fatores e variáveis determinantes de sua conceituação, tais como a existência de água potável adequada para o consumo humano, condições sanitárias regulares à convivência humana, existência de suplementos alimentares saudáveis, habitação e tratamento da saúde preventiva e curativa, acesso aos serviços e às informações de saúde. 
É muito importante prestar atenção ao impacto da corrupção no gozo dos direitos econômicos, sociais e culturais. Os Estados aceitaram, através de uma variedade de tratados internacionais de direitos humanos, em sentido amplo as obrigações relacionadas à prestação ou regulação de serviços públicos relacionados à saúde, habitação, água potável e educação. Esses serviços geram grandes contratos públicos que não só criam oportunidades para a corrupção, mas além da corrupção, eles têm um impacto desproporcional nos grupos vulneráveis e desfavorecidos, especialmente as mulheres. A corrupção generalizada em serviços de saúde ou educação impede as pessoas mais pobres de obter atendimento médico ou acesso à educação, arruína suas oportunidades e reduz seus padrões de vida de pessoas mais carentes e vulneráveis.

A recente instauração de Comissão Parlamentar de Inquérito (CPI), de autoria do Deputado Geraldo Resende (MS), para investigação acerca da existência de cartel na fixação de preços e distribuição de órteses e próteses, onde criam-se demandas artificiais direcionadas para produtos/mercadorias específicos sob a forma de órteses e próteses. Tal fato determinado segundo o requerimento exige quem são os responsáveis pelas falsas necessidades? (produtores, importadores, distribuidores), como o fazem? (meios ilegais de cooptação do serviço público/privado de saúde para comercialização) quem participa do esquema? (médicos, clínicas, hospitais, atores jurídicos). Quais são as consequências e os prejuízos causados aos Sistemas de Saúde e aos pacientes com essas práticas. (http://www.camara.gov.br/proposicoesWeb/fichadetramitacao)

Outro caso de repercussão nacional foi à operação "Dopamina" deflagrada pelo Polícia Federal em conjunto com o Ministério Público Federal, a fim de apurar fraudes para aquisição de marca-passo para o tratamento do Mal de Parkinson pelo Hospital das Clínicas de São Paulo. De acordo com as investigações, pacientes seriam induzidos pelos médicos a proporem ações judiciais para a compra dos equipamentos retromencionados.

Assim, o Poder Judiciário, induzido a erro, por laudos médicos fraudulentos, entendia haver urgência e expedia decisões, em caráter liminar, para a aquisição dos equipamentos. Ressalta-se que a compra era feita sem licitação, sempre com a mesma empresa fornecedora e com os valores superfaturados. Impende consignar que os equipamentos que, de forma regular, custariam cerca de $\mathrm{R} \$ 24$ mil eram adquiridos por $\mathrm{R} \$ 115$ mil. Consta ainda do procedimento investigatório que, no período de 2009 a 2014, ocorreram cerca de 200 cirurgias, as quais teriam gerado um prejuízo de cerca de R\$ 18 milhões. (ROCHA, 2016, p. 184) 
Em verdade, há uma rede de relações que estão imbricadas ao tema da corrupção, pois quando ela se dá enquanto causa de emendas orçamentárias supressivas, aditivas, realocativas, em tese lícita, estes atos administrativo-legislativos afetam intensamente todos os bens e interesses públicos que sofreram alguma restrição neste particular, no caso da educação (quando tem créditos reduzidos), é a qualidade do ensino que cai ou se vê prejudicada; o que se dá também na área da saúde.

\section{CONSIDERAÇÕES FINAIS}

Conforme abordado e desenvolvido no presente texto, a realização dos direitos humanos em sua dimensão positiva e prestacional por parte do Estado ficam comprometidas em face da negligência e omissão estatal, pois a sua violação é relevante para um conjunto de direitos humanos e não para, apenas, um direito isolado em si. Esta interconectividade tornase evidente quando se considera que o bem-estar humano, isto é, a saúde requer a satisfação de todas as necessidades humanas, tais como, ar, água, alimento e sexo, sociais e psicológicos, a necessidade de pertencimento a grupos de amigos, família e comunidade. $\mathrm{O}$ ponto central de uma abordagem dos direitos humanos para a saúde é garantir que os medicamentos essenciais estão disponíveis, acessíveis e de boa qualidade, em quantidade suficiente em países onde há necessidade deles.

A corrupção dificulta o cumprimento de cada uma dessas obrigações. Veja-se que, por explícita violação ao direito de igualdade garantido pelas Constituições contemporâneas e aos Tratados e Convenções Internacionais de Direitos; por outro lado, os atos de corrupção têm por consequência o tratamento diferenciado a pessoas em face do acesso aos serviços de saúde, os quais deveriam proporcionar a todos o atendimento de atender de forma isonômica. Em termos gerais, a corrupção no setor de saúde acaba ocorrendo de três modos: administração de recursos financeiros, na distribuição e compra de medicamentos e, por fim, na relação de trabalhadores da saúde com pacientes.

A obrigação de proteção exige os Estados membros protejam as pessoas de violações e infrações do direito a saúde por parte de terceiro, que fornecem bens e serviços para atendimento, seja público ou privado. Para essa finalidade, os Estados membros devem editar leis, ou ainda, políticas públicas que assegurem o acesso em condições de igualdade aos serviços relacionados prestados, devendo controlar a comercialização de equipamentos e medicamentos objetivando assegurar que todos profissionais na área de saúde, atendam a 
todos de forma isonômica, obedecendo a um a conduta ética mínima. Ainda, deverão adotar outras medidas protetivas contra os atos de corrupção (por exemplo, marketing ou publicidade enganosa por parte das empresas), regulamentação e monitoramento das pesquisas médicas, suscetíveis à manipulação e compensação às vítimas de corrupção no setor da saúde.

\section{REFERÊNCIAS}

ALBA, Luiz Eduardo Zavala de. "La Corrupción y los Derechos Humanos: Estableciendo el vínculo". La Escuela de Graduados en Administración Pública y Política Pública (EGAP) del Instituto Tecnológico y de Estudios Superiores de Monterrey, México; Consejo Internacional de Políticas de Derechos Humanos, 2009.

BOBBIO, Norberto. Da estrutura à função: novos estudos de teoria do direito. Trad. Daniela Beccaccia Versiani. Barueri: Manole, 2007.

O Futuro da Democracia. Uma defesa das regras do jogo. Tradução Marco Aurélio Nogueira. 6a Edição. Rio de Janeiro: Paz e Terra, 1986.

Dicionário de política. Brasília: Editora: Universidade de Brasília, 1 la ed., 1998.

Comentários ao Pacto Internacional dos Direitos Econômicos, Sociais e Culturais. São Paulo, 2013. Editora Clássica.

Compilação de Instrumentos Internacionais de Direitos Humanos. Provedoria dos Direitos Humanos e Justiça: Timor Leste, 2012.

DALlARI, Sueli. A Construção do Direito a Saúde no Brasil. Revista de Direito Sanitário, São Paulo v. 9, n. 3 p. 9-34. Nov. 2008 /Fev. 2009.

GUERRA, Sidney. Direitos Humanos e Cidadania. São Paulo: Atlas, 2012.

Relatório Global Corruption Report. Transparency International, 2006.

LEAL, Rogério Gesta. Patologias Corruptivas nas Relações entre Estado, administração pública e sociedade. Causas, consequências e tratamentos. Santa Cruz do Sul: EDUNISC, 2013. 
A quem compete o dever de saúde no direito brasileiro? Esgotamento de um modelo institucional. Revista de Direito Sanitário, São Paulo v. 9, n. 1 p. 50-69 Mar./Jun. 2008.

OS Efeitos Deletérios da Corrupção em Face dos Direitos Humanos e Fundamentais. Disponível em www.ajuris.org.br. Acesso em 25 de abril de 2018.

LENZA, Pedro. Direito Constitucional Esquematizado. - 20. ed. rev., atual. e ampl. - São Paulo: Saraiva 2016

PIOVESAN, Flávia. Direitos Humanos e o direito constitucional internacional. - 14. ed., rev. e atual. São Paulo: Saraiva 2013.

__. Temas de Direitos Humanos. - 5. ed. - São Paulo : Saraiva, 2012.

RAMOS, André de Carvalho. Curso de direitos humanos. São Paulo: Saraiva, 2014.

ROCHA, Lilian Rose Rocha. Corrupção: os efeitos deletérios sobre as políticas de saúde. Universitas Jus, Brasília, v. 27, n. 3, 2016 p. 173-189.

ROJAS, Claudio Nash; BASCUNÁN, Pedro Aguiló; CAMPOS, María Luisa Bascur. Corrupción y Derechos Humanos: Una mirada desde la Jurisprudencia de la Corte Interamericana de Derechos Humanos. Publicado en mayo 2014.

SARLET, Ingo. Curso de Direito Constitucional. São Paulo: Saraiva 2015

SYMONIDEZ, Janus. Direitos Humanos: novas dimensões e desafios. Brasília: UNESCO Brasil, Secretaria Especial dos Direitos Humanos, 2003.

SILVA, José Afonso. Curso de Direito Constitucional Positivo. Editora Malheiros, 2015.

SCHILLING, Flávia. Governantes e governados, público \& privado: alguns significados da luta contra a corrupção, o segredo e a mentira na política. Revista da USP, São Paulo, v. 37, 1998.

WOLKMER, Antônio Carlos. Direitos Humanos. Novas Dimensões e Novas Fundamentações. Ano X no 16/17 jan./jun. 2002. 
http://www.camara.gov.br. Data de acesso: 25 de fevereiro de 2018.

Saúde e direitos humanos/Ministério da Saúde. Fundação Oswaldo Cruz, Grupo Direitos Humanos e Saúde. Helena Besserman. - Ano 7 n. 7 (2010). - Rio de Janeiro: 2011. Acesso em: 25 de março de 2018.

\title{
CORRUPTION AND THE VIOLATION OF HUMAN RIGHTS TO HEALTH
}

\begin{abstract}
The purpose of this article is to analyze corruption against the violation of Human Right and Fundamental Health. The theory of the promotional function of law will be approached, seeking to demarcate the theoretical reference of Norberto Bobbio. In the second point, an approach will be taken on the legal literature, especially in relation to the International Human Rights Treaties and Conventions on the Right to Health. Finally, the way in which acts of corruption committed by public and private agents reach directly and indirectly, this fundamental right of second dimension, taking into account the parameters and studies carried out by the Report of the Institute of Human Rights of Monterrey in Mexico (2009), seeking to establish preventive and co-operative coping ways to the harmful effects of the corruption phenomenon, not only health, but also the right to life, dignity of the human person, equality and discrimination.
\end{abstract}

Keywords: Health. Human Rights. Corruption. Fundamental Rights. 